\title{
Los fundamentos del folklore y su vínculo con la educación ${ }^{1}$
}

\author{
Mercedes Giesecke Sara Lafosse \\ vilgie@speedy.com.pe \\ Antropóloga y pedagoga. UNMSM
}

\begin{abstract}
Resumen
El presente artículo habla sobre las politicas culturales subyacentes a las políticas educativas desarrolladas entre 1945 y 1948. Quienes lideraron este enfoque fueron dos etnólogos sanmarquinos Luis Eduardo Valcárcel, padre de la disciplina etnológica en el Perú y José María Arguedas, intérprete y comunicador entre dos mundos. El enfoque desarrollado tuvo mucha fecundidad, entre sus logros más importantes fue la apuesta por los Núcleo Escolares Campesinos (NEC), que permitió democratizar la educación, creando un proceso inconclusoj de inclusión de una ciudadanía diferenciada.
\end{abstract}

Palabras clave: Educación rural, Políticas educativas en 1945, Luis Eduardo Valcárcel, José María Arguedas, Núcleos Educativos Campesinos, Folklore, Etnología, Políticas culturales.

\begin{abstract}
The present article speaks on the underlying cultural policies to the developed educative policies between 1945 and 1948. Those who led this approach were two ethnologists of the University of San Marcos in Lima: don Luis Eduardo Valcárcel, father of the ethnological discipline in Peru and don José María Arguedas, interpreter and cultural bridge between two worlds. The developed approach had much fecundity, between its more important profits was the best done by Núcleo Escolares Campesinos (NEC), which allowed to democratized the education, creating an unfinished process of inclusion of a differentiated citizenship.

Keywords: Rural education in Perú, Educative policies in 1945, Luis Eduardo Valcárcel, José María Arguedas, Núcleos educativos campesinos, Folklore, Ehtnology, Cultural policies.
\end{abstract}

1 Agradezco la oportunidad de realizar el presente artículo, como consultoría externa, a la Dirección de Promoción Escolar, Cultura y Deporte - DIPECUD - del Ministerio de Educación y a la Licenciada Renata Teodori quien la dirige. También a mis colaboradores: Mirtha Arias, Ynés Espinoza y Andrés Ramírez por el recojo de la información en los archivos y a Bruno Yika por lo mismo y por su apoyo como asistente de investigación. 
“...no era admisible manifestar que el indio se incorporaba a la "vida civilizada”, había que colocarse en el punto de vista contrario. La civilización occidental era la que se incorporaba al indio, respetando y enriqueciendo sus cualidades ${ }^{2}$."

(VALCÁRCEL: 1981)

\section{Introducción}

Hablar de aquello que vincula al folklore con la educación, es hablar del contexto histórico y cultural; de la necesidad de pasar lista a los momentos importantes del siglo XX, en los cuales hubo la necesidad de consolidar una identidad nacional. Esta identidad no sólo pasaría por la edificación de grandes monumentos conmemorativos al centenario de la independencia, tal como ocurrió en 1921 con el presidente Augusto B. Leguía. La construcción de la unidad patria fue un sentimiento que emergía de las heridas de la derrota con Chile. Como consecuencia del análisis sobre las causas que pudieron estar a la base de esta derrota, uno de los factores sería el cultural, pues parece ser que había un divorcio entre el ideal criollo de una nación unida y el ideal de una vida centrada en la autosuficiencia del pueblo indígena. Tal como lo señalara Manuel Vicente Villarán “....el ya notable desequilibrio de la nacionalidad, derivado de la diferencia de razas y de las supervivencias oligárquicas de la época colonial”3.

Entre 1900 y 1945 la mayor preocupación era centralizar el sistema administrativo del Estado, entre ellos el sistema educativo. Se esperaba que el sistema educativo contribuyese de manera eficiente en la forja de un nuevo ciudadano. Que introdujera a la mayoritaria población del país, en ese entonces llamada india, a la civilización. El tipo de civilización que se quiso construir, fue una civilización moderna orientada al trabajo para poder aprovechar las riquezas naturales a favor del progreso moderno de la nacionalidad.

Hacia 1945 había surgido un proyecto binacional para la educación indígena, el cual se justificaba con la intención de lograr:

“...la incorporación del indio a la nacionalidad, como factor activo de producción, y de consumo, y como sujeto de cultura, constituye un proceso social no sólo pedagógico sino también económico y político (...)

...es de urgente necesidad la pronta y completa rehabilitación moral y cultural de los indígenas, para cuya consecución es indispensable que se les proporcione las mismas oportunidades educativas en ambos países, y se les reconozca igualdad de derechos e igualdad de participación en las responsabilidades cívicas"4

2 Ver: VALCÁRCEL, Luis E. (1981). Memorias. Lima: IEP, p. 350.

"Había que eliminar cualquier rasgo de coerción en los métodos didácticos de los centros educativos de la población indígena. Nuestro proyecto se fundaba en ideas muy distintas a las que, por entonces, predominaban entre los responsables de la educación pública. Para nosotros existía un enfrentamiento entre dos culturas como problema de fondo y rechazábamos lo que se denominaba "incorporación" del indígena a la "civilización occidental" (...). No era admisible manifestar que el indio se incorporaba a la "vida civilizada", había que colocarse en el punto de vista contrario. La civilización occidental era la que se incorporaba al indio, respetando y enriqueciendo sus cualidades, incorporar al hombre como se incorpora una cosa era identificar hombre y cosa. Desde el descubrimiento de América, el hombre aborigen había sufrido una enorme desvalorización como persona, cuyas secuelas se aprecian siglos después en planteamientos tan lamentables como el de la incorporación del indio a la cultura occidental. "Hombre incorporado" a la cultura occidental era lo mismo que decir sujeto en situación de esclavitud o de servidumbre, hombre disminuido y sin libertad que, para "incorporarse a la civilización", renuncia a sus hábitos, ideas, técnicas, artes, sentimientos, creencias, etc. En este proceso de enfrentamiento cultural, la misión de la escuela era de primera importancia, el educador se encargaría de discriminar varios aspectos del acervo cultural moderno que merecían ser admitidos en la cultura indígena" (p.350)

3 Manuel Vicente Villarán (1873-1958). 2003. María Luisa Rivera de Tuesta. En: Grandes Educadores Peruanos. MED, p. 48.

4 Fecha entre 1945- 1946. Ficha: MN / ALEV M. Ed 005. Referencia: Proyecto de convenio sobre Educación Indígena, entre los Gobiernos de Bolivia y Perú. Museo de la Nación, Archivo Luis E. Valcárcel, p. 2. 
Para Luis E. Valcárcel ha sido fundamental, como etnólogo, no sólo conocer la historia sino también conocer la cultura viva de los pueblos indígenas. Es su profundo conocimiento de las culturas de los pueblos indígenas lo que le llevó a preocuparse por entenderlos. Valorando profundamente las culturas indígenas como fuentes de vida y de sabiduría. Dentro de una visión clásica de la antropología, Valcárcel hace una cita de Herkovits 5 , donde explica los universales de las culturas:

"Todos los pueblos tienen algún modo de proporcionarse el vivir. Lo consiguen por medio del equipo tecnológico empleado para arrancar de su ambiente natural los medios de sostener la vida y llevar adelante sus actividades diarias (...) Ninguno vive en completa anarquía, sino que en todas partes se han hallado muestras de algún género de control político.

Ninguno está sin una filosofía de la vida, un concepto del origen y funcionamiento del universo y de cómo debe tratarse con los poderes del mundo sobrenatural para conseguir los fines deseados, en síntesis, un sistema religioso) (Herkovits 1952:31).

El pensamiento y doctrina de Valcárcel, el cual fue planteado en 1945, señalaba que las diversas culturas debían ser estudiadas con anterioridad a todo plan educativo y a todo plan de gobierno en general. Es en este sentido que:

"El propio Ministerio de Educación Pública ha establecido en la Dirección respectiva, una Sección de Folklore que mediante la activa cooperación de los millares de maestros distribuidos en todo el territorio nacional, se encargará de realizar una gran encuesta que acopie el precioso material folklórico que se va perdiendo aceleradamente. Nos proponemos conservar y difundir las bellezas del arte del pueblo en la escuela y fuera de la escuela. Para cumplir esta importantísima labor del Estado se crean las siguientes entidades:

a) El Instituto Libre de Arte Peruano

b) La sección de Folklore Musical del Conservatorio Nacional de Música

c) La Escuela Regional de Artes del Cuzco

El primero reunirá en su seno a los artistas que, por consenso internacional, son reputados como integrantes de la Escuela Peruana de Pintura. La segunda se encargará de recoger y conservar la música peruana, y la tercera tiene como principal misión provocar el resurgimiento de las artes populares que en la colonia dieron al Cuzco renombre americano. Las tres instituciones que comenzarán a funcionar este año aseguran el magnífico éxito del presentido Renacimiento de las artes"6

\section{Nociones del folklore}

Hacia 1943 la UNESCO$^{7}$ produjo un documento sobre el patrimonio cultural de la humanidad; dentro del mismo, se distinguía entre los bienes materiales e inmateriales, considerando entre estos últimos, a la cultura y a la educación. Esto es muy importante porque se crea un vínculo explícito, por el cual se reconoce que la labor educativa se asienta en el conocimiento no sólo del pasado, sino y fundamentalmente en la re-creación cultural de los pueblos a través de su forma de ser; expresada en los idiomas, el folklore y las costumbres.

5 HERKOVITS, Melville J. (1952). El hombre y sus obras. México: Fondo de Cultura Económica, 782 pp. Ficha: ALEV - FB.ET- 028 (p.14). Museo de la Nación. Archivo Luis E. Valcárcel.

6 Ficha: MN / ALEV M. Ed 008 (p.13). Fecha aproximada 1945. Museo de la Nación. Archivo Luis E. Valcárcel.

7 Ficha: MN/ALEVM. Ed 032. "PROTECCIÓN DEL PATRIMONIO CULTURAL DE LA HUMANIDAD". Esta ficha forma parte de las lecturas de Valcárcel antes de ser Ministro de Educación en 1945. Archivo Luis E. Valcárcel. 
Avanzando en la profundización del concepto de folklore, se alude a las expresiones culturales llamadas supervivencias, las que se originan: "en las poblaciones menores, aisladas, distantes de los centros principales, y en territorios remotos (no conquistados culturalmente por los estados directores), donde subsisten los primitivos grupos llamados aborígenes".

Así mismo, se precisa otra definición de folklore: "A él le interesan los elementos vivientes de las culturas que revelan un carácter arcaico, los que no son productos de la propia época en que aparecen sino que vienen desde lejos, teniendo su origen en otras a veces muy remotas épocas". 9

Dentro de los procesos en los que se ha visto involucrado el folklore, también se mantiene el énfasis puesto a su valor turístico. El turismo es de un carácter cultural, que enfoca su atención al aprendizaje de la historia a través de los restos arqueológicos e históricos, como a través de las manifestaciones artísticas y folklóricas. Así tenemos que en el IV Congreso Interamericano de Turismo ${ }^{10}$ realizado en 1952, la delegación peruana expresó lo siguiente dentro de su ponencia:

- "Conservación de la pureza y estímulos para el fomento del folklore americano. Las manifestaciones folklóricas, y entre ellas la danza, música, canciones, fiestas e industrias nativas, revelan la fisonomía ancestral y emotiva de los pueblos y constituyen fuentes, interesantes de captación para el conocimiento, la investigación y el arte. En el I, II Y III Congreso Interamericano de Turismo se han aprobado Resoluciones tendientes a la conservación, pureza y estímulo de las manifestaciones folklóricas e industriales típicas de cada país".

- "Concursos y estímulos para el fomento del Arte Popular Americano. El arte popular de los países americanos constituye la más pura y auténtica expresión del alma de los pueblos, cuya raigambre artística se nutre en las más remotas culturas que florecieron en suelo americano. (...)

Donde puede observarse la pureza de estas manifestaciones del ingenio popular es en aquellos pueblos que por su fuerte porcentaje racial autóctono o que por su grado de mestizaje mantienen con celo su tradición que determina un riquísimo folklore (...)

El acervo folklórico de los países americanos es un filón todavía no muy bien explotado para el fomento del turismo, especialmente, en cuanto al arte popular, música, trajes y danzas típicas se refiere, constituyendo para el investigador y el turista una positiva atracción y compensación del viaje".

El concepto de folklore se va modificando constantemente. Al inicio de los 40, tenía un fuerte contenido étnico, evocando las supervivencias y añorando nostálgicamente la presencia de un pasado a través de una cultura indígena aún no transformada por el proceso educativo de la cultura dominante. Hacia fines de los 50, se revisa el concepto de folklore precisando y re-contextualizándolo a un país, a una sociedad predominantemente urbana, por efecto de las constantes y crecientes olas migratorias.

Como consecuencia del avance de la escuela en el campo, la ciudad ya no puede percibir al folklore como la expresión verdadera de una cultura indígena. Porque esta cultura indígena se va adaptando a la vida citadina. Lo cual replantea la comprensión de la cultura indígena en la vida moderna. Tal como lo señala Guillermo Fuerte Díaz ${ }^{11}$ :

8 Ficha: ALEV-FB.ET.063. Folklore (sic). Aproximadamente en 1943. Autor: Carlos Vega. Instituto de Foklore. Tomo I, Argentina

9 Ficha: ALEV-FB.ET.018. El Problema de la tradición como mito y poesía. Autor: Miguel de Fernandy. En: Anales de Arqueología y Etnología. Tomo X 1949, Universidad de Cuyo.

10 Ponencia de la Delegación Oficial Peruana. IV Congreso Interamericano de Turismo. Capítulo V. Sección B. Punto B. Lima marzo de 1952. Museo de la Nación. Archivo de Luis E. Valcárcel.

11 FUERTE DÍAZ, Guillermo. "El indio y su cultura". Lima, enero de 1958. En: Separatas. Sección Antropología. Museo de la Nación. Archivo de Luis E. Valcárcel. 
“...la verdadera base de la cultura indígena actual debemos de buscarla en sus instituciones sociales, en el significado hondo que tiene para ellos la posesión de la tierra $(\ldots)$

En cuanto al futuro del indio, se debe de encauzar sus actividades en un tono concordante con la vida moderna, introduciendo claro está elementos y técnicas materiales de trabajo. Esto se hará con acción de la Antropología (...) encuadrado dentro de lo telúrico de los grupos humanos indígenas del Perú, o sea la tierra"

Esta cita lo que quiere es distinguir el folklore, de lo que es la verdadera cultura indígena. Reforzando una separación disciplinaria, entre la disciplina del estudio del folklore como estudio de las supervivencias artísticas; y la disciplina etnológica como el estudio holístico de la cultura indígena. Según Bruno Jacovella, el folklore es el patrimonio cultural tradicional que recrean los grupos étnicos que han migrado, o se han modernizado. En este sentido, la disciplina folklórica es una rama de la etnología cuyo fin es "reconstruir históricamente dicho patrimonio en su integridad morfológica y funcional, investigar la difusión y procedencia de sus elementos así como sus cambios en el tiempo y en el espacio". ${ }^{12}$

A lo largo de toda la década de 1940, se pueden percibir los constantes entrelazamientos entre distintas visiones acerca de la diversidad cultural, las que implican dos maneras de enfocar la educación.

La primera es la visión que se asienta en el enfoque de la comprensión del indígena, con una preocupación atenta a su ser como persona y que lo asume en una cercanía afectiva comunicativa. En este sentido, Arguedas propiciaba un método para acercar dentro del diálogo a dos culturas. Una de ellas, más urbana y castellanizada y la otra, más rural y vernáculo-hablante. Así, él comentaba de su experiencia como profesor en Sicuani:

"Muchas veces, nuestras clases las dedicamos a leer los informes de los alumnos sobre las observaciones hechas en el campo o en la calle; entonces cada quién podía hablar, opinar, disertar. (...) Con esta labor teníamos la conciencia de que contribuíamos a divulgar la intimidad espiritual del pueblo que vive en nuestra región (...). Y por otro lado, inducíamos a los alumnos a estudiar su país, a conocerlo bien" 13. "(...).Aprendimos a saber que lo esencial en un hombre, lo que verdaderamente le da valor y dignidad, es su pureza de espíritu, su nobleza, su conciencia de solidaridad humana, su sinceridad para juzgar el valor de los demás y el suyo propio; nuestras clases fueron siempre horas dedicadas a la superación del espíritu, a la formación del carácter; al conocimiento del verdadero deber humano, y en medio de todo esto cumplimos nuestro deber de instruir y de dar enseñanzas"14

La segunda visión se asienta en el enfoque educativo que privilegia los aspectos externos de la cultura indígena. Ello impide un acercamiento comunicativo al ser indígena, relevando la marcada diferencia entre los portadores de una cultura castellana "civilizada" y los portadores de una cultura extraña, diferente, en algunos casos percibida como huraña. Caricaturizándola:

"El indio tan apegado a su tierra y a su paisaje sufre terriblemente la separación de su lar nativo (...). Fuera del microcosmos de su ayllu nada existe digno de aprecio (...). Se ha ligado a la tierra con la fuerza enorme de las raíces de los árboles quebradeños y fuera de ella es un ser triste, un vencido, un hombre para quien la vida no tiene razón

12 Ficha: ALEV-FB.ET-030. "Los conceptos fundamentales clásicos del folklore. Análisis y crítica”. Bruno C. Jacovella. En: Cuadernos de Instituto Nacional de Investigaciones folklóricas. Buenos Aires. 1960. pp 27-48.

13 Pumaccahua. Revista editada en Sicuani. Cuzco. José María Arguedas. Enero de 1940. Páginas 82-83.

14 "Carta a los alumnos del colegio Mateo Pumacahua de Sicuani”. Publicada en La verdad, Sicuani, 4 de Junio de 1942. Lima 12 de Mayo de 1942. Tomado de: José María Arguedas: ¡Kachkaniraqmi! ¡Sigo siendo; Textos esenciales. Fondo Editorial del Congreso del Perú. 2004. Carmen María Pinilla (Recopilación y notas) (p.148) 
de ser" (p. 1045). (...) "Por otra parte, la mentalidad solidaria, hosca y únicamente abierta en los vínculos socializantes del ayllu, al procedente de su mismo linaje (...) al adorador de su mismo tótem y al que profesa las mismas costumbres y guarda las mismas tradiciones, hizo que el indígena viese no sólo con extrañeza sino con repudio y odio a todo elemento ajeno a su ayllu. De allí su aversión al "Pu rica" al que camina, al que no es del mismo pueblo, "lactaruna" (p.1095-1096) ${ }^{15}$.

Ambas visiones sobre el indígena, ayudan a comprender la presencia de dos enfoques que serán determinantes al momento de convivir a duras penas dentro de las políticas educativas. En última instancia, con las actitudes que expresarán los docentes dentro del aula.

En la década de los 50, se aprecia una mayor conciencia de los procesos de falta de inclusión del indígena a la vida nacional, regional y local, aún es denominado "indio" o indígena. Se presentan tres formas de definir los procesos culturales, económicos y sociales que se viven en esta década: primero se propuso la reflexión desde el mestizaje; en un segundo lugar, se reflexiona desde el folklore; y en un tercer momento, se discute desde el limitado papel de la educación desde su fracaso cultural, por la gran deserción de población andina de la escuela:

"En el Perú, la segregación cultural sigue siendo cruel, estilizante y anacrónica aunque se ha progresado algo en los últimos 20 años. El indio aparece todavía como un personaje inmerso, rezagado en siglos a pesar de su infatigable esfuerzo de supervivencia y de adaptación a los grandes cambios - cambios a saltos- que da constantemente la cultura que le rodea. (...). El caso del indio se ha convertido en el Perú en un problema de creciente gravedad. El proceso de mestizaje es, como ya dijimos, de una lentitud pavorosa. Se produce en las ciudades y en ciertas aldeas. Pero en las grandes regiones pobladas exclusivamente por indios (...) la cultura india permanece íntegra. La misma economía y la segregación cultural lo rodea y aísla como un anillo de hierro"16

En la perspectiva de la definición de folklore, se tiende a relacionarlo a un concepto de cultura sin escritura que "se conserva", de un pueblo sin historia escrita. Nos muestra las tradiciones, si bien no les niega una dinámica propia, las coloca en un lugar relativamente aislado del contexto urbano local, regional y nacional, como la definición que se coloca a continuación:

"Así nos encontramos con que el carácter principal del Folklore es su naturaleza iletrada, su naturaleza de cosa que se conserva, no son el profesor ni la escritura, su naturaleza de pueblo sin historia escrita...” (...) “...la mejor definición que podemos dar es que Folklore, como ciencia, es el estudio de las tradiciones". ${ }^{17}$

Arguedas, habla del mestizaje como forma de dotar al indígena de herramientas culturales, que le sirvan para interactuar con los entornos "civilizados", es decir castellanizados, insertados en un mercado ocupacional, habiendo superado la segregación cultural o "el anillo de hierro". El enfoque, a cargo del Ministerio de Educación Pública, si bien muestra una preocupación por la falta de la integración del indígena a la educación pública, supone una hipótesis, la de utilizar el sistema educativo como una palanca para lograr una homogenización cultural o de "civilización". En esta propuesta, emerge una noción de hombre universal, pero ausente de toda apreciación que reconozca la relevancia de la

15 DELGADO VIVANCO, Edmundo. "El forasterito en el Folklore" (Tomado de la Revista Waman Puma, del Cuzco). En: Peruanidad vol. III, $\mathrm{N}^{\circ}$ 14, Junio-Agosto. Órgano del Pensamiento Nacional. Dirección de informaciones. Ministerio de Gobierno. Lima. 1943.

16 ARGUEDAS, José María. "El complejo cultural en el Perú y el Primer congreso de Peruanistas". Tomado de la Revista América Indígena $\mathrm{N}^{\circ}$ 2, México, 1952, pp 131-139. En: Carmen María Pinilla (Recopilación y notas) (2004). José María Arguedas: ¡Kachkaniraqmi! ;Sigo siendo; Textos esenciales. Fondo Editorial del Congreso del Perú, p. 191.

17 MUELLE, Jorge. "Cultura y Folklore”. Tomado de la Revista Cultura y Folklore. N ${ }^{\circ} 31$. Año III. Lima, set 1953. pp. 1014-1015. En: Acerca del Folklore. Municipalidad de Lima. 1991. (pp 23 - 24). 
diversidad cultural como un elemento fundamental, sobre el cual desarrollar herramientas educativas culturalmente inclusivas. Se privilegia la democracia como principio de inclusión, sin embargo, no hay una acción eficaz que compense la carencia de herramientas culturales que garanticen el ejercicio de los derechos democráticos, de estas culturas indígenas ${ }^{18}$. Existió la preocupación por hacer un inventario, para conocer el grado de abandono escolar. Se buscó compensar esta situación dando la gratuidad de enseñanza de la secundaria común y técnica en el año 1958:

“...por Decreto Supremo No 10 del 28 de Marzo último, se estableció en toda la República la gratuidad de la enseñanza secundaria común y técnica para el primer año de estudios y por Decreto $\mathrm{N}^{\circ} 16$ del 21 de Mayo del presente año se hizo extensivo este beneficio a todos los grados de la enseñanza común y técnica en vista de haberse promulgado la Ley $\mathrm{N}^{\mathrm{o}} 12996$ que destina rentas para esta gratuidad, tan ansiada por mucho tiempo por el pueblo peruano.

La labor de estudio emprendida gracias al inventario de la Realidad Educativa del Perú demuestra que de una promoción que comienza la educación primaria, sólo el $14.45 \%$ llega a estudiar educación secundaria común y técnica. Se ha inferido así mismo que del alumnado que ingresa en el primer año de primaria únicamente llega al $5^{\circ}$ de secundaria el 4,13\%, registrándose una deserción del 95,87\%"19.

En la década de los 60, la migración del Ande a las urbes costeñas se muestra en toda su pujanza. Este nuevo contexto, muestra nítidamente la evolución del concepto de folklore como disciplina útil a la educación; asimismo nace el sentimiento de preocupación por introducir nociones urbanas y civilizadas como la higiene ${ }^{20}$. Se notará que la producción intelectual de Arguedas, en relación al vínculo entre folklore y educación, tiene eco en educadores importantes como Emilio Barrantes y en lingüistas como Inés Pozzi-Escot. Lo interesante de esta época es la profundización en la comprensión del fenómeno folklórico y su fomento a través las instituciones educativas, así como la promoción que se le da en su difusión nacional.

Arguedas habla de la conservación de las costumbres, del modo de ser de los indios y de los procesos de movilidad social; que van dejando atrás, el estático aislamiento geográfico. Reconoce que los procesos de cambio implican una inminente influencia de la cultura occidental $^{21}$. Sin embargo, reconoce que estos encuentros culturales no han eliminado la cultura indígena, es por ello que recomienda el estudio del cuento indígena como un método del folklore para el estudio de esta cultura:

“...el folklore como modo de conocer la inteligencia, la sensibilidad, las preferencias (...), es muy importante para que un maestro se desenvuelva acertadamente en un medio que puede ser muy especial" (p.75). (...) "La educación no consiste solamente

18 "Bases de la Educación Fundamental. Si uno de los principios básicos de la democracia consiste en la ayuda de las zonas menos desarrolladas, es obvio que el objetivo principal de la educación fundamental debe ser referido al individuo, en relación a su familia y a la sociedad. Lo esencial es la comprensión de los sentimientos, actitudes y patrones culturales del hombre. Esto demanda el esfuerzo personal de cuantos tienen fe en el pueblo, en la eficacia del progreso democrático y de los que poseen las habilidades necesarias para enseñar".

Luis A. López Galarreta. "Educación Fundamental y alfabetización en el Perú". Ministerio de Educación Pública. Boletín de la Reforma Educativa $N^{\circ}$ 10. Enero-Abril. Lima-Perú, 1958.

19 MINISTERIO DE EDUCACIÓN PÚBLICA. Boletín de la Reforma Educativa. $N^{\circ} 10$. Enero-abril. Educación Secundaria. Gratuidad de la enseñanza Secundaria común y técnica. Lima-Perú. 1958. (p.19)

20 José Jiménez Camacho. "Un alto valor puneño. José Domingo Choquehuanca”. En: Revista del Instituto Americano de Arte N, ${ }^{\circ}$ 9. 1965, Puno.

21 Ver José María Arguedas. "Relaciones entre geografía, la raza, la economía y las costumbres en nuestro país". En Revista Cultura y Pueblo N. ${ }^{\circ}$ 2. Comisión Nacional de Cultura. Ministerio de Educación Pública. Casa de la Cultura 1964. 
en dar instrucción (...) hay que darla siempre de acuerdo con los incentivos característicos espirituales que en cada comunidad mueven al hombre" (p.78) $)^{22}$

Arguedas insiste en el camino del diálogo y del acercamiento mutuo como método para conocer a una cultura. Toma como base el descentramiento de los educandos respecto de la existencia de una diversidad cultural y, ello requiere educar una conciencia de la diferencia, para incluir a la otra cultura, para ello se tiene como método conocerla, a través del folklore como disciplina de estudio. Por este motivo, Arguedas y muchos otros, revaloraron la cultura indígena en sus expresiones culturales generales, tales como: la música, la danza, el cuento, los rituales y las propias costumbres y formas de organización que sustentaban las expresiones artísticas propiamente dichas. Hay una doble preocupación en Arguedas, una tiene que ver con la necesidad de formar en los educandos, una inteligencia abierta al diálogo entre culturas. La otra preocupación, tiene que ver con la importancia que él le daba a la promoción del folklore como una expresión auténtica del pueblo. Así tenemos, su participación en la Comisión Nacional de Cultura de 1963, donde velaba por delimitar el valor educativo del folklore, tal como se muestra a continuación:

"La comisión calificadora podrá prohibir la interpretación de canciones manifiestamente inmorales en consideración de tipo público. El Sr. Villanueva informó haber escuchado huayno pornográfico, al respecto el Sr. Gálvez Saavedra que por denuncia personal del Señor Abelardo Arriola Ledesma, miembro del Jurado calificador, recomendó al empresario del coliseo "Dos de Mayo" se prohíba la presentación de actuaciones pornográficas. Sobre este punto, el Sr. Arguedas ordenó al señor Gálvez Saavedra oficiar al Trovador Andino, prohibiéndose las canciones de tipo pornográfico". 23

Esta doble preocupación de Arguedas, nace de dos intenciones claramente diferenciadas. Una, es la intención de formular el concepto de folklore como disciplina de estudio al interior de la formación educativa y dentro del sistema escolar y educativo en general. La otra, concibe utilizar los concursos folklóricos organizados por el Estado, como un instrumento de apropiación mutua de espacios. Donde se encuentra el funcionario, como Arguedas (que es educador y un buen intérprete cultural), con los artistas folklóricos que recién se van fogueando en estos nuevos espacios oficiales de carácter educativo nacional. Esta participación artística será por un lado, propia; y por otro, será modificada en sus aristas que puedan herir la sensibilidad de lo que en la cultura occidental podría llamarse lo moral. Pero al final de cuentas, lo sustantivo es que se da un nuevo espacio para propagar expresiones folklóricas y artísticas, haciendo de estos concursos una plataforma donde lo popular y culturalmente indígena podría ser apropiado por cualquiera dentro del espacio nacional, siendo este un camino de construcción hacia la identidad nacional. Esta forma de concebir los concursos folklóricos, dentro de parámetros educativos y morales, se distancia de otras posturas que más bien entienden el folklore como un hecho espontáneo y local. No entienden el folklore desde el enfoque educativo, sino que lo confunde con la propia disciplina etnológica. Como en el caso siguiente:

"Para que el folklore sea tal, tiene que reunir o cumplir tres requisitos que constituyen su esencia, son: lo anónimo, lo tradicional y lo popular". (...) El concepto de folklore no encierra criterio ético ni estético. No hay folklore feo ni bonito, moral, panteísta, profano, etc. De allí que el folklore no puede ser objeto de concurso. Estos son fenómenos sociales que no pueden ser objetos de concurso. Cualquier manifestación

22 "El cuento folklórico como fuente para el estudio de la Cultura”. Ministerio de Educación del Perú. Escuela Nacional de Músicos y Danzas Folklóricas. Conferencias (mimeo), pp. 14-18. 1965.

23 "Acta de la sesión convocada para estudiar la reforma de reglamento de inscripción de intérpretes folklóricos del país, que se dedica a la divulgación musical coreográfica". En: Registro de Intérpretes. Comisión Nacional de Cultura, 1969. 
folklórica es tan igualmente importante como las demás, por más grande o pequeña magnitud que tenga. Cada una tiene peculiaridades, contenidos y valores individuales y tradicionales propios." ${ }^{24}$

La cita anterior, utiliza de manera incorrecta la palabra folklore, pues el folklore es la disciplina que estudia las manifestaciones culturales del pueblo indígena y por lo tanto, dialoga con sus sujetos a través de sus manifestaciones culturales. Por este motivo, es muy relevante conocer a profundidad el pensamiento de Arguedas cuando habla de la importancia del folklore como ciencia que tiene un método que sirve, por ejemplo, para analizar los cuentos que el pueblo inventa. Porque el cuento folklórico:

“...refleja la realidad de la vida del pueblo que los muestra: retrata sus costumbres, sus creencias, la idea que tiene del bien y del mal. Muestra cómo están instituidas las autoridades que imponen su voluntad o ley: Si en tal pueblo hay ricos y pobres, en qué grado están diferenciados unos con otros y porqué intentamos demostrar, analizando muy someramente, el cuento "el lagarto", recogido en un pueblo del departamento de Ayacucho, hasta qué punto es cierto todo lo que afirmamos sobre el valor que muchos cuentos tienen para estudiar la vida de los pueblos.

Para realizar el análisis de los cuentos el folklore como ciencia ha creado un método luego de muchos años de experiencia en la recopilación y en el estudio de este material. Una finalidad principal persigue la aplicación de este método: descubrir la procedencia del cuento, su origen geográfico y humano, cuál pueblo lo inventó y cómo era ese cuento, en su forma, en su contenido, cuándo fue creado, los cuentos se difunden, viajan por todo el mundo." ${ }^{25}$

Por otro lado, el proceso de migración ha permitido que muchas danzas andinas ceremoniales, se extingan o se readapten. Debido a lo que Arguedas señala:

“... (Con el paso) de la población indígena a las escuelas, el culto a los dioses locales, especialmente a las montañas (wamanis, aukish, apu) se convierte en patrimonio de los viejos, y las danzas y las ceremonias con que se manifiesta este culto se desintegran. Algunas desaparecen y otras cambian de función: se convierten en recreativas, se secularizan. (...)Lo mágico se transforma en popular y así se hace más permanente (...) De ese modo, especialmente, la danza se convierte en un vínculo, asimismo, más vasto de la comunidad y puede aspirar a serlo de la nación misma. Es lo que ha ocurrido, por ejemplo, con la danza del Huaylas". ${ }^{26}$

La acción intelectual y profesional de Arguedas por enriquecer el ideal de identidad nacional, como un crisol de culturas, ha dado sus frutos en la reflexión que Emilio Barrantes hizo sobre la problemática de la "castellanización inmediata de la población indígena". Barrantes cuestionó que la comunidad nacional deba ser expresión únicamente de la supuesta "superioridad del español sobre el quechua y el aymara":

"La unidad e integración de la que hablamos no puede significar en ningún caso la imposición de un molde sino la mayor nivelación posible de los habitantes en lo que concierne a la satisfacción de sus necesidades primordiales, las oportunidades para el mejoramiento y la garantía de los derechos, así como la posesión por todos de una conciencia y un espíritu comunes que, sin embargo, coexisten con la variedad de las manifestaciones culturales porque en ellas se refleja el vigor natural y el carácter de un pueblo."27

24 J. Moisés Aguilar V. "El folklore de Danzas en el Departamento de Puno". En: Revista del Instituto Americano de Arte. N. ${ }^{\circ}$ 9, p. 68. Puno, 1965.

25 José María Arguedas. ¿Qué es el folklore? Estudio de los cuentos. Método de Análisis. En: Revista Cultura y Pueblo N. $^{\circ}$ 6. Abril - Junio,. publicaciones de la Comisión Nacional de Cultura. Lima,.1965.

26 "Navidad y Huaylas, de lo mágico a lo nacional". Tomado de: El Comercio, Lima 22 de enero de 1967, p.27. En: José María Arguedas. ;Kachkaniraqmi! ;Sigo siendo! Textos esenciales. Fondo Editorial del Congreso del Perú. 2004. Carmen María Pinilla. (p..566).

27 "La Educación en el Perú y las Lenguas Aborígenes". En: Revista Cultura y Pueblo N. ${ }^{\circ}$ 7. Comisión Nacional de la Cultura. Ministerio de Educación. Julio a diciembre, 1965. 
Para Barrantes, se lograría la unidad nacional a partir de un mayor desarrollo "de la personalidad histórica del pueblo indígena", lo que permitiría acelerar su proceso de integración. De esta manera, se pondría fin a esta "situación injusta y perjudicial".

Arguedas ve en la migración los procesos cambiantes de la cultura en las barriadas, lo cual hizo sentir con notoria fuerza en su novela de los Zorros, por lo cual en la ciudad la realidad cultural del indígena, sigue cuestionando el proceso educativo homogenizador. Se pretende forzar la castellanización sin respetar el desarrollo de la personalidad histórica del indígena, como decía Emilio Barrantes. Como dijo Inés Pozzi-Escot, en ese sentido, se debería introducir una castellanización científica que prevea la enseñanza de idiomas como primera y segunda lengua, o como dialecto ${ }^{28}$.

El adecuado enfoque cultural permite que al respetar el idioma vernáculo, en el contexto de la escuela, traiga como consecuencia la necesidad de enseñar el castellano como segunda lengua. De tal manera, se refuerza la lengua materna y, a la vez, se le dota de un nuevo instrumento cultural a la cultura local, para que desarrolle sus vínculos con los entornos regionales y nacionales castellano hablantes, permitiendo que su lenguaje no se extinga, porque:

"Las leyendas y mitos cosmogónicos andinos, el trabajo artesanal, la expresión musical; reflejan sus ideas, sus aspiraciones, sus creencias religiosas, sus preocupaciones materiales, su ideología, se transforman o expresan a través del lenguaje"22.

\section{Políticas culturales para el sistema educativo}

El trabajo pionero de Luis Eduardo Valcárcel, cuando fue Ministro de Educación (1945-1947), se explica en gran medida en su defensa del indio a través de las políticas que implantó. Entre las diversas capacidades que fue forjando para realizar su labor de Ministro, se encuentra aquella dada por la etnología, disciplina a través de la cual forjó su propia visión de la problemática del indígena y desarrolló los métodos que le permitieron revalorar el ser del indio. Tal como se puede apreciar en su experiencia universitaria hacia 1909:

"Hubo una completa coincidencia entre los ideales propugnados por (Albert) Giesecke $^{30}$ como educador y los defendidos por nuestro grupo estudiantil; es más, sus enseñanzas nos dotaron de los medios necesarios para hacer efectivas nuestras intenciones. Se interesó mucho por los indios y fue el primero de nuestros maestros en llevarnos a las comunidades indígenas, en el campo nos educó en la observación de aspectos particulares que registrábamos en unas libretas de apuntes. Nos enseñó métodos estadísticos, a realizar encuestas y preparar cuestionarios, introdujo el método de lecturas dirigidas que permitían a los alumnos hacer adecuados resúmenes y cuadros sinópticos y, sobre todo, nos ayudó a conocer el Cuzco, pues nos hizo voltear los ojos hacia nuestra realidad y nos enseñó a observarla con actitud crítica". ${ }^{31}$

Este aprendizaje etnológico lo llevó a valorar la enorme importancia de visitar por él mismo los pueblos, especialmente cuando fue Inspector Departamental de Instrucción en 1912. Su interés mayor fue observar el tipo de relación que establecían los maestros con sus alumnos indígenas ${ }^{32}$. Su indigenismo promovía "un sentimiento de fraternidad hacia

28 Ver: Inés Pozzi - Escot. "La situación lingüística en el Perú”. En: Educación Año III, N. ${ }^{\circ}$, La revista del maestro peruano. Lima. 1972.

29 Silvio Ferrari Le Cari. “A propósito del Folklore”. En: Runa 4. Revista del Instituto Nacional de Cultura. Lima-Perú. Junio de 1977.

30 Rector de la Universidad San Antonio Abad del Cusco entre 1909 y 1922.

31 Luis E. Valcárcel. Memorias. 1981. IEP. (p.139-140).

32 Ibíd.: 173-174 
el indio", pero el ambiente político de su época no hacía eco de esta sensibilidad que considerase al indio otra persona con los mismos derechos de ser escuchado, de "difundir sus tradiciones y sus creaciones artísticas". Estas ideas fueron motivo de persecución ${ }^{33}$.

Junto a esta preocupación por revalorar los derechos del indio, cuando era Director del Museo de la Universidad del Cuzco (1920), desarrolló una “campaña en la defensa de los monumentos arqueológicos y coloniales" ${ }^{\text {"34. }}$.

Cabría decir que Valcárcel se fue preparando, desde la disciplina etnológica, para pensar el problema de la cultura y de la educación desde una perspectiva de reconocimiento de la diversidad cultural, principio para la formación de una identidad cultural peruana. Para ello, reflexionó la cultura indígena en su expresión artística, como en su posible integración a la vida nacional a través de la escuela. Por otro lado, sumada a su capacidad etnológica, estaban sus capacidades arqueológicas e históricas, complementando así, con conocimiento de causa, el sustento de las raíces de la cultura indígena, para hacer que su propuesta de integración indígena a la nación, que si bien partía del presente, se engarzara con el pasado y se proyectara al futuro dentro de una visión de la identidad peruana a partir del reconocimiento e inclusión de la diversidad cultural.

Estos escasos pincelazos nos muestran la preparación que tuvo Valcárcel antes de llegar a ser Ministro de Educación. Una vez que llegó a ser Ministro, lo primero que hizo fue convencer al Congreso para que dotara a este sector del Presupuesto necesario para iniciar sus reformas de políticas culturales y para la propuesta educativa que desarrollaría:

\begin{abstract}
"(al sustentar el presupuesto ante el congreso) Era necesario dejar establecido que nuestros planes no obedecían a una concepción superficial de simples amantes de la cultura, sino que eran una respuesta a problemas de fondo, cuya solución constituía una verdadera necesidad, tanto como la de cualquier problema económico. Desde una perspectiva etnológica, había que mostrar a esos parlamentarios -acostumbrados a recorrer el Perú muchas veces sin comprenderlo a cabalidad- la compleja realidad cultural que nuestra patria encierra para que así se dieran cuenta que cualquier plan de desarrollo pasaba por enfrentar el problema de la diversidad cultural" 35 .
\end{abstract}

El Presupuesto al sector aumentó casi en un 90\%. Más de la mitad del cual, fue destinado a mejorar los "miserables" haberes de los maestros. Una parte significativa del Presupuesto fue destinada a mejorar la calidad de la Dirección Artística y Extensión Cultural. Así como para "entidades de un sentido trascendental para la cultura peruana, como el Museo de este nombre y sus institutos: de Arte Peruano, (de Estudios Históricos) y de Estudios Etnológicos" ${ }^{" 36}$. Parafraseando a Luis. E. Valcárcel, gran educador, él previó la necesidad de resolver todos los problemas administrativos y económicos del Ministerio de Educación, para "transformarlo" de un ente administrativo de "centros escolares a un agente impulsor del desarrollo cultural":

"Por eso aparte de trabajar para darle a la educación escolar y técnica el mayor nivel posible y las mejores condiciones para su desempeño, nos preocupamos por desarrollar la educación artística, para lo cual se crearon instituciones como la Escuela de Arte Dramático, la Compañía Nacional de Teatro, la Sección Folklórica del Conservatorio Nacional de música, el Archivo Nacional de Folklore y la Escuela Regional del música del Cuzco" ${ }^{\text {37: }}$

33 Ibíd.: 246-247

34 Ibíd.: 14

35 Ibíd.: 349

36 Ficha: MN / ALEV M. Ed 041, 1946, pp. 2 y 3. Archivo Luis E. Valcárcel.

37 Memorias. 1981. Luis E. Valcárcel. IEP, p. 348. 
Valcárcel en unos casos innovó algunas Direcciones dentro del Ministerio y, en otros casos, recreó el sentido de la educación campesina; así mismo renovó la Dirección de Educación Artística y extensión cultural, la que fue creada dentro de la Ley Orgánica de Educación Pública, promulgada el 1 ro de Abril de 1941, -antes de su ingreso como ministro de educación en 1945-. Dicha ley, en su capítulo IX, artículo 53, dice a la letra “esta Dirección servirá de nexo entre el Ministerio de Educación y el Patronato Nacional de Arqueología"38. Esta Dirección, bajo las capacidades que le otorga dicha Ley, le corresponde además lo siguiente:

"Art. 54.- Corresponden a esta Dirección:

$3^{\circ}$ - Extender y difundir la cultura científica, artística y literaria.

$4^{\circ}$ - Multiplicar las Bibliotecas Populares en la República; (...)

$9^{\circ}$ - Fomentar las artes útiles de los aborígenes; (...)

$14^{\circ}$ - Cuidar de que se lleven registros de especies arqueológicas, de monumentos precolombinos y coloniales, de objetos históricos y artísticos y de documentos históricos manuscritos o impresos;

$15^{\circ}$ - Impulsar los estudios folklóricos y bibliográficos y velar por la conservación del folklore nacional." ${ }^{39}$

En los ítems 3, 9 y 15, se sustenta la creación de la Sección de Folklore para el "cultivo de las artes populares", de forma científica. Dentro de esta Sección se debía:

"Dirigir y coordinar la investigación del folklore y las artes populares en el país; recoger el apropiado material de estudio; formar un archivo documental; estudiar. La formación de un museo Folklórico y elaborar material educativo en esta rama de la cultura" ${ }^{40}$

Las innovaciones a nivel de la estructura institucional llevaron a ampliar la importancia del estudio del folklore y de la cultura popular en general con fines educativos. Para ello, se creó el Museo de la Cultura Peruana y el Instituto de Estudios Etnológicos. Como parte de sus objetivos, se debía desarrollar la investigación y la presentación de la evolución histórica de la cultura peruana como un conjunto. A continuación, podemos leer un fragmento del Decreto Supremo de marzo 30 de 1946, en el que se da la creación de estas Instituciones:

"DECRETA.- Art. $1^{\circ}$.- Créase en la capital de la República y con carácter nacional, el Museo de la Cultura Peruana. Art. $2^{\circ}$.- Destínese con este fin el local de la Avenida Alfonso Ugarte en que funcionó la Sección de Arqueología del Museo Nacional (...) Dado en la casa de Gobierno, en Lima, a los treinta días del mes de Marzo de mil novecientos cuarentaiseis. (FDO) José Luis Bustamante y Rivero (Fdo) Luis E. Valcárcel" 4 .

Cabe mencionar, que mientras que Valcárcel fue Ministro de Educación, propició una ley universitaria, dentro de la cual, se daba la creación de un conjunto de Institutos de Investigación de carácter sociocultural, en la Universidad de San Marcos. Estos institutos iniciaron sus actividades en 1946, el de Etnología estuvo bajo su dirección:

"La ley universitaria, aprobada mientras fui Ministro de Educación, hizo posible la fundación en la Universidad de San Marcos de varios institutos, que iniciaron sus actividades en 1946, bajo la dirección de distinguidos especialistas. Julio C. Tello en Arqueología; José M. Valega en Historia; Julio Chiriboga en Filosofía; Fernando Tola en Filología; José Gálvez en Literatura Peruana y Folklore; Javier Pulgar Vidal

38 Ficha: MN / ALEV M. Ed 051, 11.1 de Abril de 1941. Archivo Luis E. Valcárcel.

39 Ibíd.

40 Ficha: MN / ALEV M. Ed 020. Julio 1946. Páginas 13 y 14. Ver también Ficha: MN / ALEV M. Ed 008. Fecha aproximada 1945. Museo de la Nación. Archivo Luis E. Valcárcel.

41 Ficha: MN / ALEV M. Ed 050, 12. Marzo 30 / 1946. Archivo Luis E. Valcárcel. 
en Geografía y el de Etnología a mi cargo, con cuya fundación se podría decir que se introdujo oficialmente el aprendizaje de la etnología en el Perú" ${ }^{42}$.

Cuando, anteriormente, mencioné que Valcárcel había recreado el sentido de la Educación Campesina, me refería a su visión de la Educación rural como parte del problema indígena, el indio inmerso en la pobreza y rodeado de muchos problemas, como: "el de salud, el de su economía, el de su educación o pedagógico: el de sus derechos o jurídicos"43. Organizó el Consejo Nacional de Coordinación de Asuntos Indígenas, que él mismo presidió "para coordinar la labor de sus Despachos en lo relativo al problema indígena" ${ }^{44}$. La relación de dichos despachos es la siguiente:

“- La Dirección de Educación Técnica: Organizando la Escuela Técnica primaria, la escuela secundaria agrícola para preparar administradores rurales y, la educación Agrícola Profesional o Agronómica en la Escuela Nacional de Agricultura.

- La Dirección de Educación normal preparando al magisterio Rural indígena en las Escuelas Normales Rurales. (...)

- La dirección de Educación Artística y Extensión Cultural, restaurando el folklore nacional y recopilando lo existente para darle aplicación en la educación indígena. (...)

- El Sr. Director del Servicio Cooperativo Peruano Norteamericano orientando la Educación Técnica, etc." ${ }^{45}$.

Para Valcárcel, la educación rural indígena "salvaría al país del intelectualismo improductivo y aseguraría la capacitación del campesino para su defensa económica, cultural y social" ${ }^{\prime 4}$. El ardor de Valcárcel por la mejora de la educación campesina, estaba basado en su firme convicción que la educación debería ser un medio para promover su desarrollo económico y por ende, utilitario, pero revalorando su contexto socio cultural. Así decía: "nos orientamos hacia una escuela activa, queremos llegar a la masa indígena con una escuela útil" ${ }^{47}$, siendo la etapa inicial la campaña de alfabetización en entornos netamente campesinos. Como el caso de los aymaras, en la región del lago Titicaca, lugar donde se promovió un proyecto binacional entre Perú y Bolivia. Sin embargo, Valcárcel tenía muy claro el problema de la "inferioridad económica" de la población indígena en el Altiplano, era conciente de la necesidad de tierras para los indios y, que no podía abordar el problema del reparto de tierras desde la posición que ocupaba. Como Ministro de Educación, señaló que era preciso: "defender nuestro acervo histórico y nuestro futuro (...) La América Latina espera mucho de los países representativos de su propia cultura" 48 .

El propósito de crear una escuela indígena activa, radicaba en que los campesinos se sintiesen escuchados dentro de ella, lo que permitiría desarrollar un sentido de pertenencia de los campesinos hacia "su" escuela. Para lograr este cometido, desarrolló los Núcleos Escolares Campesinos, tal como él mismo lo describió:

"Cada uno (de los Núcleos Escolares Campesinos) estaría integrado por una escuela central, alrededor de la cual se nuclearían 15 o 20 escuelas seccionales. La escuela central tenía que ser el modelo y guía de las otras, además debía establecerse en un punto equidistante para facilitar las comunicaciones. De esa manera el centro del núcleo se ubicaba en el pueblo más grande de la zona y en cada comunidad o poblado

42 Memorias. 1981. Luis E. Valcárcel. IEP. P. 363

43 Problema indígena. Arequipa, 1 de noviembre de 1945.

44 Ibíd.

45 Ibíd.

46 Ibíd.

47 "El Perú no tiene porque atacar al Ecuador". Por Alberto Galeano. En: Agencia noticiera Latinoamericana. Boletín $\mathrm{N}^{\circ} 233$ ANLA. Paseo de la Reforma 146-6 México D. F. Aproximadamente en el año 45.

48 Ibíd. 
pequeño se instalaba una seccional. Los maestros de la escuela nuclear tenían que ser los mejor preparados, capacitados en diversas materias, con conocimiento de agricultura y ganadería, artesanía, higiene y primeros auxilios, aparte claro está, de ser competentes alfabetizadores y quechuahablantes" ${ }^{49}$

Según el Plan Educativo de $1947^{50}$, se debía realizar una amplia campaña de alfabetización pre-escolar. Parte de esta campaña, debía ser realizada en lenguas indígenas en los departamentos de Puno, Cuzco, Huancavelica, Ayacucho y Apurímac. En cuanto a la educación del campesinado, habían elegido tres lugares estratégicos por su alta densidad cultural indígena. El primero fue lago Titicaca, con un proyecto de capacitación a los maestros y de alfabetización de su lengua materna. El segundo, fue el Valle del Mantaro donde se desarrolló el proyecto de las escuelas rurales campesinas. El tercero, el valle del Urubamba donde se desarrolló el proyecto de las fases de la investigación etnológica.

El esfuerzo de Valcárcel estuvo concentrado en encontrar el mejor método para la alfabetización del niño indígena. Pudo comprobar que la enseñanza de la lectura por medio de la lengua materna era exitosa, pues se debía a que despertaba eficazmente el interés del niño. Una vez que el niño conociera la lectura y la escritura en su lengua materna, se podría proceder a la enseñanza en castellano e inclusive se aspiraba a la enseñanza de la lecto-escritura en tres idiomas: quechua, aymara y castellano. Estos resultados se lograron a partir de la técnica de enseñanza de la lectura por medio de la lengua materna, creada por la señora Elaine Townsend ${ }^{51}$. Aplicada por el normalista Don Jorge Alberto Paniagua, con la ayuda de las lingüistas Olivia Shell y Elena Ross, del Instituto Lingüístico de la Universidad de Oklahoma ${ }^{52}$.

Los frutos de la gestión de Valcárcel, mientras fue Ministro de Educación, fueron muchos, entre ellos, el apoyo que le dio a Arguedas para que prosiguiera sus estudios sobre los cambios culturales en el Valle del Mantaro, a causa de la migración ${ }^{53}$. Por otro lado, el Instituto de Estudios Etnológicos de Puno le informó a Valcárcel, que estaba fracasando la enseñanza importada en castellano a los niños aymaras y quechuas porque "no entienden nada de lo que le dicen sus maestros", a diferencia de lo que ocurría en el caso de la amazonía:

"Los niños campas, machigengas, huitotos, etc. de las selvas tienen mejor suerte que los quechuas y aymaras del Altiplano de Puno, porque allá ya se les está enseñando en sus propias lenguas maternas, debido al esfuerzo del Instituto Lingüístico de Verano que está a cargo de elementos extranjeros." ${ }^{, 54}$

A fines de la década del 50, el entusiasmo por los estudios culturales seguía vigente. Se desarrollaba el Plan Nacional de Integración de la Población Aborigen ${ }^{55}$. El cual buscaba mejorar las condiciones de vida y de trabajo de las comunidades campesinas, promoviendo el desarrollo económico, social y educativo. El aspecto de la educación estaba a cargo del Núcleo Escolar Campesino de Vicos-Ancash.

49 Memorias. 1981. Luis E. Valcárcel. IEP. P. 353. Este cita alude al contexto en el cual Luis. E. Valcárcel era Ministro de Educación (1945-1947).

50 Ficha: MN / ALEV M. Ed 043. 1947. Archivo Luis E. Valcárcel.

51 Elaine Mielke Townsend: A Woman of Few Regrets. By Doris Au MacDonald, July 27, 2000. En: http:// www.jaars.org/e_townsend_bio.shtml. La señora Elaine Townsend antes de traer al Perú su método, había conducido campañas de alfabetización y preparado materiales de instrucción para 17 minorías lingüísticas en México. Vivió en el Perú entre 1946 y 1968 y recibió las "Palmas Magisteriales" en reconocimiento del gobierno peruano a su labor en el Instituto Lingüístico de Verano (ILV).

52 Ficha: MN / ALEV M. Ed 044. Noviembre 23, 1946. Archivo Luis E. Valcárcel.

53 Ficha: MN / ALEV C A 175. 20 de Julio de 1954. Archivo Luis E. Valcárcel

54 "Niños Aymaras y quechuas del Altiplano del Titicaca y su educación". Por: El Instituto de Estudios Etnológicos-Puno. 2 de enero de 1958.

55 Archivo de Luis E. Valcárcel. "Plan Nacional de integración de la población aborigen”. 1959. 
Hacia el año 1978, Valcárcel, poco antes de morir, seguía promoviendo la educación contextualizada a la realidad cultural y seguía pidiendo, que se le diera mayor apoyo a las expresiones culturales nativas, o también llamadas folklore; como un aspecto importante de proyección escolar. Con plena convicción manifestaba que "la meta es peruanizar al niño para que los ciudadanos del mañana se sientan orgullosos de haber nacido en un país de tradición" 56 .

Desde la perspectiva profesional de José María Arguedas, hay dos temáticas importantes a desarrollar. La primera se refiere a una discusión teórica relativa al indígena, su cultura, su lengua, su demanda por la escuela y también sobre la importancia de sus expresiones culturales, artísticas y de su cultura en general, o también llamada folklore, que en el fondo sugiere un enunciado y una fundamentación de políticas culturales. La segunda se refiere a las políticas culturales asumidas por la administración estatal, expresadas en las normas, instituciones y acciones que se dieron en el Ministerio de Educación en relación a la promoción del folklore en sus múltiples expresiones y a su utilidad para la escuela.

En relación a la primera temática, hacia 1943 se asumía que era necesario tomar en cuenta el folklore peruano como parte de la civilización nacional. Se entendía por folklore las creencias, costumbres, tradiciones, trabajo e idioma de los indígenas ${ }^{57}$.

Sobre el tema de las lenguas aborígenes se inició la propuesta de la alfabetización en lenguas maternas para los niños aborígenes, fue una alfabetización en lengua materna, lo que Arguedas llamó el método cultural, por lo cual manifestó que "el primer paso consiste en lograr que el individuo de lengua sin alfabeto tenga conciencia del valor y de la importancia de su idioma nativo"58. La política cultural era de relevancia y de prioridad y se debía realizar a través de la política educativa; en este sentido, la enseñanza de la lengua tendría como finalidad mejorar la comunicación en la sociedad en su conjunto ${ }^{59}$. Incluso, hacia 1972 se consideraba al:

"Perú como un país multilingüe, carente de una lengua general (...) papel que debería jugar el castellano (...) Esto no significará de ningún modo la eliminación de las lenguas nativas, las cuales deberán ser respetadas y cultivadas. (...). En las zonas del monolingüismo castellano, se promoverá el aprendizaje de lenguas nativas, aprendizaje que será recomendado e incluso obligatorio para especialistas que van a entrar en contacto con monolingües nativos, a fin de intensificar la comunicación a nivel nacional, en tanto no se alcance una lengua común." ${ }^{60}$

Al recordar las décadas entre el 20 y el 60, viene a la memoria la gran demanda democrática del pueblo campesino desde sus caseríos y comunidades campesinas por lograr que se construyan escuelas en sus localidades ${ }^{61}$. Al inicio de la década del 20, la castellanización se hizo en negación de la cultura vernácula, pero a fines de los 30 e inicios de los 40, paulatinamente se va insertando la mirada cultural en los procesos educativos. Como fruto de las intensas experiencias y debates en torno a la relación entre escuela y comunidad campesina, y así surge con fuerza el tratamiento del folklore.

56 Ficha: ALEV-FB.ET-003. "30 años de la didáctica del Folklore”.1978. Archivo Luis E. Valcárcel.

57 Manuel Bustamante Jerí. Inspector de Instrucción Primaria de la provincia de Huamanga. Apuntes para el folklore peruano. Ayacucho. Impresión: La Miniatura. 1943. Página 1.

58 José María Arguedas. “Un método para el caso lingüístico del indio peruano”. En: Historia, Revista de la Cultura, $N^{\circ}$ 6. Lima. José María Arguedas. Enero-julio, 1944. Página 43.

59 Alberto Escobar. "Para qué sirve la lingüística al maestro de lengua". En: Educación. La revista del maestro peruano. Lima. Año III, $N^{\circ} 9,1972$

60 Hans Spann del Solar. "Primer Seminario Nacional de Educación Bilingüe. Un antiguo problema y un nuevo cambio". En: Educación Año III, N 9, Revista del maestro peruano. Lima. 1972.

61 Emilio Morillo Miranda. "La educación desde la concepción andina". En: Cuadernos Arguedianos. Revista de la ESNF. Dirección de Investigación. Lima, II época, Año 4, N. ${ }^{\circ} 4$. Diciembre del 2001. 
Según Merino, el folklore puede ser empleado en la “educación, recreación, para conocer la organización política y social, la historia de una comunidad o del mismo país, para la teoría ritual, mitológica, y para mejorar los programas de cambios culturales que proponen los antropólogos del desarrollo" ${ }^{2}$. Lo más importante de este enfoque es que prioriza la necesidad de plantear una política cultural, donde se entendería al folklore no sólo como algo utilitario, sino como la expresión auténtica de la cultura aborigen. Así el folklore, es entendido como disciplina que sirve para revalorar una cultura oral, tal como lo precisa Arguedas:

"Para el folklorista o el antropólogo, el cuento oral es (...) una fuente de conocimiento valiosísimo del modo de ser de cada pueblo. En el cuento, el hombre de ciencia que estudia las causas que fijan las diferencias de conducta, el modo de ser de cada pueblo, (...) halla en forma directa y viviente, la descripción de lo que se llama la cultura material y cultura espiritual de los grupos sociales". ${ }^{63}$

En esta segunda temática, quiero iniciar recordando que no ha habido una política cultural explícita respecto a la diversidad cultural del pueblo peruano, como política de Estado orientada a una integración basada en mutuas valoraciones. Sin embargo, en la década del 40 emergió una iniciativa que marcó un derrotero histórico del sistema educativo y del sector educación para la inclusión del indígena a través de la escuela. Los éxitos y fracasos de la política cultural empleada en ese sector, se pueden apreciar con toda nitidez hasta el día de hoy. En medio de todo ello, lo más resaltante en la escuela sigue siendo el fundamental rol del docente. ¿De qué manera interpreta y aplica la ley el maestro? ¿Tiene capacidad de acción y de fuerza? ¿En qué medida adaptará los planes y programas de estudio a la diversidad sociocultural "de nuestro territorio"? Preocupación de gran vigencia aún para nuestros días ${ }^{64}$.

Es con Valcárcel y con Arguedas que se logra, a nivel normativo, institucional y de proyectos, construir una consistente propuesta de política cultural que nace en el Ministerio de Educación y que ha continuado viva hasta nuestros días, a través de los procesos migratorios y de los medios de comunicación. Siendo su origen un contexto mayormente rural hacia los inicios de los 40 , fue toda una novedad introducir en los medios oficiales la discusión sobre políticas culturales dentro del campo educativo y el significativo incremento del presupuesto público para la promoción del folklore y de la cultura. Viendo que la cultura era considerada una rama del Ministerio de Educación ${ }^{65}$. Merino precisaba la manera en que ello se fue realizando:

"Especial mención merece el Patriarca de la Antropología Peruana, Dr. Luis E. Valcárcel, quien inició el estudio científico de la Etnología y el folklore en el Perú, siendo Ministro de Educación, al señalar los fines de la Sección de Folklore y Artes Populares en el Ministerio de Educación (R. S. 3479 de 30-X-1945).... (...)

"El análisis de fuentes documentales se constriñó a obtener material del Archivo de Cuentos Históricos del Museo de la Cultura. La recopilación, origen de ese Archivo, fue ejecutado por el Dr. José María Arguedas, siendo Jefe de la Sección de Folklore del Ministerio de Educación, en cuyo carácter la realizó. Posteriormente, autorizado por Resolución Ministerial de 1951, dicho archivo pasó al citado Museo" ${ }^{66}$.

62 Mildred Merino de Zela. “Hacia una teoría del Folklore Peruano”. Tomado de: la Revista Folklore Americano. $N^{\circ} 18$, 1974. En: Acerca del Folklore. Municipalidad de Lima. 1991

63 José María Arguedas. “¿Qué es el folklore? La literatura oral. El cuento”. Revista “Cultura y Pueblo”. N 3. Julio - Septiembre 1964. Página 10.

64 Max H. Miñano G. "El programa es el esfuerzo para dirigir la educación”. Tomado del diario "El oriente". En: Peruanidad. Órgano del pensamiento nacional. Dirección de informaciones. Ministerio de Gobierno. Lima. Julio. Vol. III, $\mathrm{N}^{\circ} 15.1943$

65 Manuel Vegas Castillo. Decreto Supremo N ${ }^{\circ}$ 48. Tomado de: Comité Interamericano de Folklore. 28 de Agosto de 1962.

66 Mildred Merino de Zela. "El tipo cuento de fórmula. Folklore del Perú". En: Ciencias Antropológicas N. 1. Seminario de Antropología. Instituto Riva Agüero. PUCP. Lima. 1969, pp. 58-59. 
"Con (Francisco) Izquierdo (Ríos) colabora en la primera gran encuesta Magisterial de folklore y ambos publican Mitos, Leyendas y cuentos peruanos. (...)En enero de 1953 es trasladado como jefe del Instituto de Estudios Etnológicos del Museo de la Cultura" $"$.

La idea de conservar el folklore nacional, es decir las tradiciones populares, es porque tiene un alto valor educativo. Es "deber del Estado", considerarlo "patrimonio espiritual del país", merecedor de su reconocimiento y difusión. Es bajo este sustento político que se crea la Sección de Folklore y Artes Populares, cuyos fines fueron la investigación del folklore, recojo y uso del material folklórico en colaboración con los maestros y alumnos, la conservación fotográfica y de filmes, la formación de un Museo Folklórico y de un Archivo Musical folklórico, la elaboración de material folklórico con fines educativos, la organización de una biblioteca folklórica, la publicación de una revista de folklore peruana y otras publicaciones, y la realización de acciones que intensifiquen y divulguen el folklore y las artes populares. ${ }^{68}$

En el año 1946, a través de una Resolución Suprema, se creó “el registro para la inscripción de conjuntos ejecutantes de música vernacular" dentro de la sección de folklore y artes populares de la Dirección de Educación Artística y Extensión Cultural, del Ministerio de Educación ${ }^{69}$. Arguedas tuvo una enorme preocupación porque se respetara la autenticidad del vestuario y de las expresiones artísticas folklóricas, tal como nos lo cuenta su hermana Nelly:

"Los domingos íbamos al Coliseo Cerrado Nacional, que quedaba cerca de mi casa, en la Victoria. Él tenía la misión de supervisar el vestuario con que se presentaban los artistas de cada región. Debía ser auténtico, típico; de los contrario no daba su visto bueno, pues como Jefe de la Sección de Folklore (y Artes Populares), despacho de la Dirección Artística y Extensión Cultural del Ministerio de Educación (...) era muy estricto en el cumplimiento de sus funciones y no permitía que los usos y las costumbres de los bailes típicos se modificaran"70.

Arguedas también se preocupó por conseguir buenas grabaciones de la música folklórica, principalmente andina, pues él mismo manifestó que entre los años 1946 y 1950 fue "la edad de oro" del folklore de los "coliseos" de Lima"" Vio con mucho entusiasmo la difusión del folklore andino y el estudio del mismo:

"La verdaderamente prodigiosa difusión de géneros musicales indígenas como el huayno (al que en la sierra norte se le llama también "chuscada" y "cachua"), el huaylas, el santiago (música de marcación del ganado) y los carnavales pueden constituir una prueba de liberación progresiva del pueblo "serrano" (los tradicionales indios y mestizos) del real o simulado menosprecio que demostraban en las ciudades por su música nativa. (...) Esta inmensa población constituye el mercado de la industria del disco folklórico, industria que se ha incrementado con la misma velocidad con que la migración de serranos a Lima"72.

67 Mildred Merino de Zela. Servicios Administrativos oficiales. En: José María Arguedas. Vida y obra. 1970.

68 José Jiménez Borja. Director de Educación Artística y extensión Cultural. Museo de la Cultura. Instituto de Estudios Etnológicos dirigido al Director del Museo Nacional de Historia. Oficio $\mathrm{N}^{\circ} 3918.7$ de Noviembre de 1945.

69 "Registro para la inscripción de conjuntos ejecutantes de música vernacular - Resolución Suprema". Lima 3 de Julio de 1946.

70 Testimonio de Nelly Arguedas. En: PINILLA, Carmen María. 1999. Arguedas en Familia. Cartas de José María a Arístides y Nelly Arguedas, a Rosa Pozo Navarro y Yolanda Pozo. PUCP. Página 319.

71 José María Arguedas y Milton Guerrero. “La difusión de la música folklórica andina. Clasificación de un catálogo de discos”. En: Ciencias Antropológicas \# 1. Seminario de Antropología. Instituto Riva Agüero. PUCP. Lima. 1969.

72 Ibíd. : 20 
La labor que Arguedas inició conjuntamente con Valcárcel en el Ministerio de Educación, oficializó en el sistema educativo la inclusión de la cultura popular o folklore. Rápidamente Arguedas obtuvo un reconocimiento de su talento profesional como etnólogo y artista. Así, el comentó:

"Yo fui al Cuzco enviado por el Ministerio para reorganizar la Escuela de Bellas Artes y fundar la de Música. No sabes con cuánto entusiasmo y afecto me recibieron los intelectuales cuzqueños. Di una charla en la universidad y cumplí mi tarea con buen éxito. Ahora las dos escuelas trabajan activamente y cumplen un papel muy útil para el Cuzco" "73.

Él prosiguió animando los concursos folklóricos escolares porque creía firmemente que a través de ellos, los maestros iban conociendo el ambiente cultural y los aspectos fundamentales de la sociedad e historia de los pueblos. Tal como señalaba Gamaniel Arroyo Ponce:

"Las comunidades, se vinculan entre sí y con los maestros y los alumnos de sus escuelas; participan eficaz y vivamente en las difusiones folklóricas; reafirman sus tradiciones al mismo tiempo que se recrean. (...) presenciar los concursos que se realizan en la capital del distrito o de las provincias como si concurrieran a sus fiestas principales" 74 .

No podemos terminar, sin antes mencionar que en agosto de 1963, fue nombrado Director de la Casa de la Cultura del Perú. Al año siguiente, publicó el primer número de la Revista "Cultura y pueblo". Asimismo, también dirigió el número 2 de la Revista Peruana de Cultura. ${ }^{75}$

Hacia finales de los sesenta, la preocupación de la educación técnica ya se había plasmado en una política de construcción de redes de planteles de enseñanza artesanal en el país. En donde el único requisito para ingresar a éstos, era saber leer y escribir ${ }^{76}$. Pero por otro lado, la preocupación por la investigación etnológica se mantenía viva con los proyectos de José María Arguedas en la Universidad Agraria de la Molina. Donde propuso un plan de estudio de la cultura, tomando como centro las fiestas y la literatura oral, dicho proyecto sería propuesto como el proyecto central de la Facultad de Ciencias Sociales para el estudio de la sociología rural. ${ }^{77}$

\section{Conclusiones}

Al iniciar la investigación, nos planteamos un par de hipótesis que han sido plenamente confirmadas. Por un lado, que el folklore ha tenido históricamente, distintos enfoques culturales que sustentaron su desarrollo, que es útil conocerlos y actualizarlos para impulsar desde el folklore la recuperación de las diversas matrices culturales vivas, puesto que aún no se ha resuelto de manera adecuada la adecuación cultural de la educación en el país.

Valcárcel y Arguedas, dentro del Ministerio de Educación, van a desarrollar dos perspectivas centrales que son complementarias. Valcárcel es el padre de la Etnología y subrayará la necesidad de realizar estudios etnológicos para el mayor conocimiento de

73 Carta N. ${ }^{\circ}$ 35. De: José María Arguedas a Arístides Arguedas. Lima, 2 de agosto de 1951. En: PINILLA, Carmen María. 1999. Arguedas en familia. Cartas de José María a Arístides y Nelly Arguedas, a Rosa Pozo Navarro y Yolanda Pozo. PUCP, p. 222.

74 Gamaniel Arroyo Ponce. “Los concursos Folklóricos Escolares en la Provincia de Tarma”, p. 194. En: Folklore Americano. Órgano del Comité Interamericano de Folklore. Año IV, N 4, Lima, Perú. 1956.

75 Mildred Merino de Zela. Servicios Administrativos oficiales. En: José María Arguedas. Vida y obra. 1970

76 La Prensa. "Promoción Artesanal en los Programas de Educación Técnica". 15 de septiembre de 1968.

77 Carta N. ${ }^{\circ}$ 64. De: José María Arguedas a J. V. Murra. En: Las cartas de Arguedas. PUCP. 1996. Edición de John V. Murra y Mercedes López - Baralt. 6 de enero de 1969. 
los pueblos indígenas y la adaptación de la educación a sus características. Buscó que la educación fuese una herramienta que potenciara los saberes locales y que incluyera algunas nociones de la modernidad bajo la premisa del respeto. Concebía la identidad nacional a partir del reconocimiento de la diversidad cultural. Él manejaba, antes de las olas migratorias, la noción de folklore como supervivencias culturales de tiempos remotos; asimismo, resaltó el deber estatal de proteger el patrimonio material e inmaterial. Por último, creyó necesario recuperar los restos arqueológicos, históricos y las manifestaciones de folklore para la promoción de un turismo cultural que, además de producir ingresos, fuese un medio para la recuperación de la autoestima colectiva y del orgullo de vivir en un país con tradiciones.

Por otro lado Arguedas, discípulo de Valcárcel, aportó una mayor definición del folklore como disciplina y rama de la etnología. Formuló su método cultural para la educación, éste consistía en enseñar la disciplina folklórica a los docentes, a través de esta disciplina, se esperaba llegar a conocer el espíritu de un pueblo y de su cultura. El objetivo era educar la sensibilidad y la inteligencia para el ejercicio del diálogo entre culturas para la inclusión del pueblo, a partir del reconocimiento de su diversidad cultural. Se trataba de incluir las diversas expresiones folklóricas del pueblo en la escuela para adecuar la enseñanza a su modo de ser. Para ello, fue importante trabajar las expresiones populares en los colegios, tales como el cuento, el baile, el canto y las costumbres. Con niños monolingües, la castellanización debiera hacerse a través de una alfabetización inicial en la lengua materna. Los concursos folklóricos tuvieron como finalidad educar a la sociedad entera en una nueva sensibilidad de tolerancia y reconocimiento de las diversas culturas en el seno de una misma nación.

En segundo término, nos planteamos averiguar de qué manera intervino el folklore como un referente cultural para el sistema educativo y las políticas educativas que desarrollaron Valcárcel y Arguedas como protagonistas. Por lo expuesto, se puede decir que fue dicho contexto el que dio origen a un acercamiento empático y comunicativo con los pueblos indígenas y migrantes. El gobierno actuó con políticas culturales que emergieron del propio Ministerio de Educación, el cual se había convertido en un "impulsor de la cultura" del pueblo. Haciendo de la educación una herramienta de integración del campesino a la nación. A través del lenguaje del folklore, de la discusión de sus significados y métodos, se fundamentó la acción política hacia la implantación de políticas culturales a mediados de $\operatorname{los} 40$, las que han perseverado en el tiempo hasta nuestros días. 